\title{
The influence of suburban land use on habitat and biotic integrity of coastal Rhode Island streams
}

\author{
Suzanne M. Lussier • Sara N. da Silva • \\ Michael Charpentier • James F. Heltshe • \\ Susan M. Cormier • Donald J. Klemm • \\ Marnita Chintala $\cdot$ Saro Jayaraman
}

Received: 10 October 2006 / Accepted: 11 May 2007 / Published online: 13 June 2007

(C) Springer Science + Business Media B.V. 2007

\begin{abstract}
Watershed land use in suburban areas can affect stream biota through degradation of instream habitat, water quality, and riparian vegetation. By

Although this manuscript was reviewed in accordance with official procedures of the U.S. Environmental Protection Agency (EPA), its content does not necessarily reflect EPA policy. Mentioning commercial products or facilities does not necessarily mean that EPA or the U.S. federal government endorses them.
\end{abstract}

S. M. Lussier $(\bowtie) \cdot$ M. Chintala $\cdot$ S. Jayaraman Office of Research and Development, National Health and Environmental Effects Laboratory (NHEERL), Atlantic Ecology Division (AED),

U.S. Environmental Protection Agency,

27 Tarzwell Drive, Narragansett, RI 02882, USA

e-mail: lussier.suzanne@epa.gov

S. N. da Silva

Nelson, Pope \& Voorhis, LLC, Melville, NY, USA

M. Charpentier

Computer Sciences Corporation,

U.S.E.P.A., NHEERL, AED, Narragansett, RI, USA

J. F. Heltshe

University of Rhode Island, Kingston, RI, USA

S. M. Cormier

National Center for Environmental Assessment,

U.S.E.P.A., Cincinnati, OH, USA

D. J. Klemm

National Exposure Research Laboratory,

U.S.E.P.A., Cincinnati, OH, USA monitoring stream biotic communities in various geographic regions, we can better understand and conserve our watershed ecosystems. The objective of this study was to examine the relationship between watershed land use and the integrity of benthic invertebrate communities in eight streams that were assessed over a 3-year period (2001-2003). Sites were selected from coastal Rhode Island watersheds along a residential land-use gradient (4-59\%). Using the rapid bioassessment protocol, we collected biological, physicochemical, habitat, and nutrient data from wadeable stream reaches and compared metrics of structure and integrity. Principal component analyses showed significant negative correlation of indicators for stream physicochemical, habitat, and instream biodiversity with increasing residential land use (RLU) in the watershed. The physicochemical variables that were most responsive to percent RLU were conductivity, instream habitat, nitrate, and dissolved inorganic nitrogen (DIN). The positive correlation of DIN with percent RLU indicated an anthropogenic source of pollution affecting the streams. The biotic composition of the streams shifted from sensitive to insensitive taxa as percent RLU increased; the most responsive biological variables were percent Ephemeroptera, percent Scrapers, percent Insects, and the Hilsenhoff biotic index. These data show the importance of land management and conservation at the watershed scale to sustaining the biotic integrity of coastal stream ecosystems. 
Keywords Assessment · Land use · Monitoring ·

Streams · Urbanization

\section{Introduction}

Biological assessment of streams integrates the condition of the watershed from tributaries to mainstem through the exposure and response of indigenous aquatic communities (Barbour et al. 1999) and is reportedly the most effective means of evaluating cumulative impacts from nonpoint sources (Karr 1991). Studies in various geographical regions have shown a relationship between land use/cover and ecosystem condition (Karr and Schlosser 1978; Roth et al. 1996). Increasing urbanization has been linked with ecological degradation of streams in a number of studies throughout the United States that report declining species diversity and loss of sensitive species (Freeman and Schorr 2004; McBride and Booth 2005; Urban et al. 2006; Walsh et al. 2005; Wang and Kanehl 2003). Studies have also shown that watershed-scale indicators are more predictive of stream biotic communities than those at the local reach scale (Allan 2004; Potter et al. 2005; Roy et al. 2005).

This research focused on wadeable streams along the coast of Rhode Island and their relationship with land uses in the upstream watersheds, along a gradient of residential urbanization. Degraded stream ecosystems can carry pollutants such as contaminants from runoff, nutrients, and excess sediments to receiving coastal waters and salt marshes.

The term "urbanization" is often used to describe increasingly populated areas (cities) and associated loss of agriculture or forest to development. Although our sites are primarily within suburban residential watersheds, they include a mix of other land uses. For our study sites, we use the definition of "urban" from Wheeler et al. (2005) as "development in a watershed, such as building construction, that changes land use typical of rural areas (e.g., farming, grazing) to uses more typical of residential and industrial areas (e.g., retail, suburban residential areas, plants and factories)."

Geographic regions vary in the extent to which land use affects ecosystem integrity and our understanding of these effects depends on relating the results of site-specific studies using similar biotic indicators and techniques to evaluate responses of stream habitat and communities along land use gradients (Snyder et al. 2003). Areas changing from agricultural land use may exhibit different indicators of stress than those changing from forested to residential land use (RLU) (Wang et al. 1997). By studying effects of urbanization in watersheds at various geographic regions, we can acquire data that better explain characteristic differences and causes of variability (Carroll and Jackson 2005), which in turn can help conservation managers protect critical habitat and ecosystem integrity. Wheeler et al. (2005) suggested that more information is needed on biological effects of specific components of urban development, such as highway, commercial, or residential uses. We suggest that it is also important to understand the relative input from various land-use stressors within a watershed in order to affect change. Our study focused on the condition of streams that drain into salt marshes along the Rhode Island coast from forested watersheds with increasing RLU, with the intention of extending the comparison to the receiving marsh condition in future research. The purpose of our study was to determine the effects of increasing urbanization of coastal watersheds and associated changes in physicochemical, nutrient, and habitat characteristics on stream macroinvertebrate assemblages. We employed the rapid bioassessment protocol (RBP) (Barbour et al. 1999) for assessing wadeable streams, measuring habitat, physicochemical, and biological indicators along a gradient of percent RLU. Our objectives were to (1) identify the relative contributions of physical, chemical, and biological metrics that served as indicators of land use degradation, (2) investigate changes in macroinvertebrate species composition that correlated with increasing RLU, and (3) examine our data for patterns and thresholds for application by watershed managers.

\section{Methods}

Site descriptions

Eight sampling sites were chosen to represent a range of anthropogenic land use in their watersheds (Fig. 1). These coastal watersheds were selected from those used in a study by Wigand et al. (2001) on the effects of human disturbance on salt marshes, with the intention of a future comparison of stream and receiving salt marsh conditions with increasing percent RLU. 


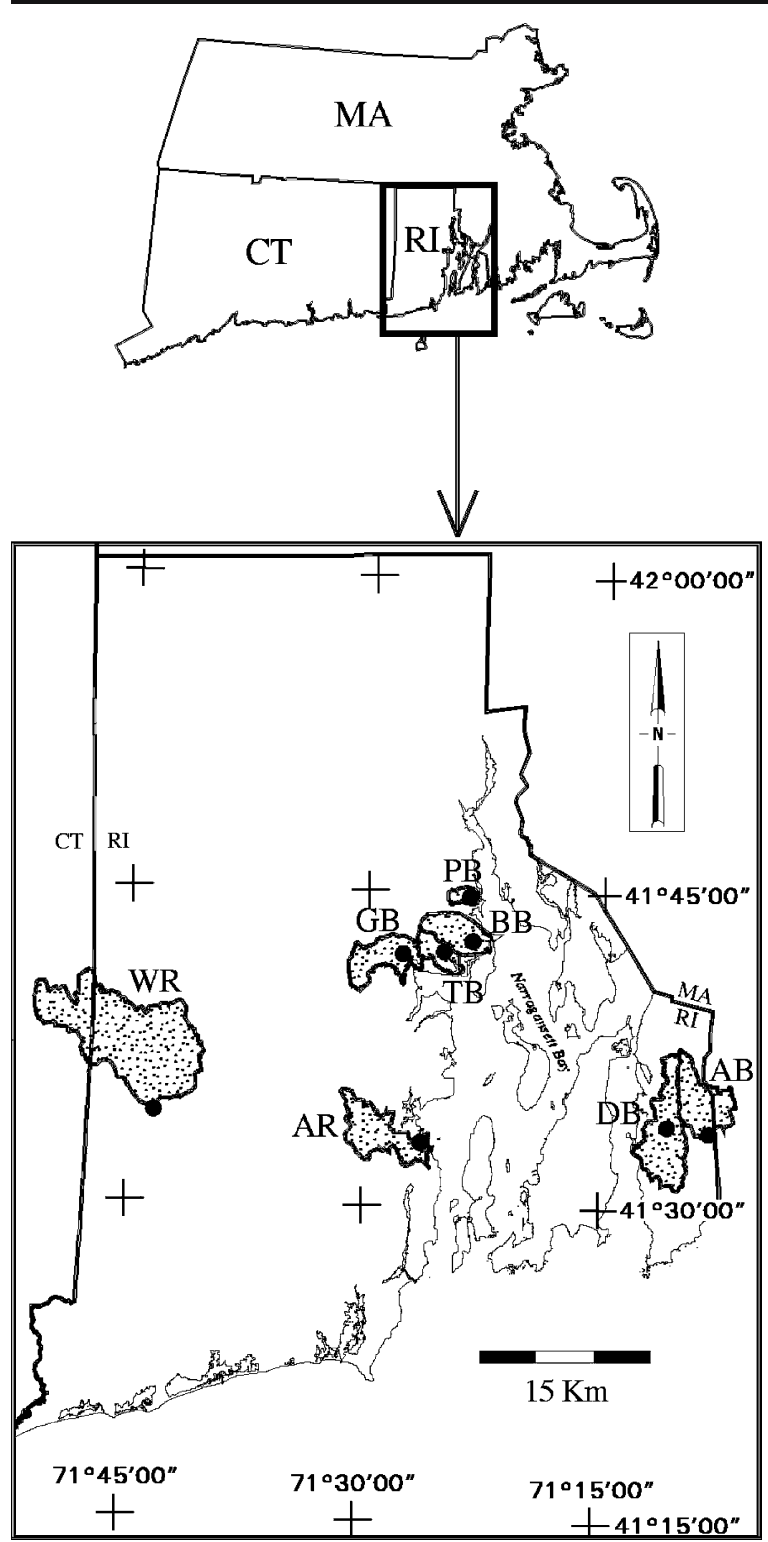

Fig. 1 Location of stream sites in Rhode Island with delineation of coastal watersheds

Wigand et al. characterized the watersheds by the relative amounts of natural land types (forested, brushland, and inland wetland) and human-altered types (residential, agricultural, industrial and commercial, and recreational). Ten subestuaries were selected from the main basin of Narragansett Bay that had similar geomorphology and with no known point sources of nitrogen. The terrain for each watershed was developed from its topography and hydrography. Riparian zone vegetation for all sites was characterized by red maple swamps (Lussier et al. 2006).
Our stream sites were selected along a gradient of 4-59\% RLU (Table 1). Sites from 4-17\% RLU included two Rhode Island reference sites for wadeable streams [Wood River (WR) and Adamsville Brook (AB)], sites from 24-38\% RLU included mixed business and residential use, and sites from 53-59\% RLU had streams running through or adjacent to densely developed residential areas (RIDEM 2002). Stream order ranged from 1st to 4th, and while we would have preferred a more consistent stream order among our sites, we were restricted to selecting state reference sites and urbanized streams that drained into the preselected salt marshes.

Rhode Island has two sub-ecoregions (Omernik 1987): Narragansett-Bristol Lowlands Region (NBLR) and Southern New England Coastal Plains and Hills Region (SNECPHR). With our small sample size, biological differences between the two regions could not be discerned, and the two sub-ecoregions were analyzed collectively. As recommended by the RBP (Plafkin et al. 1989), stream data in RI have been assessed according to sub-ecoregions, as well as collectively; the WR has served as the single reference site for the SNECPHR and the State, and $\mathrm{AB}$ as the single reference site for the NBLR (da Silva 2003). All sites in this study, with the exception of the WR, are classified as NBLR. By including both state reference sites, we can compare our stream site data to both the State and NBLR reference sites. The watersheds were delineated with 15-min (1:24,000 scale) topographic maps from the United States Geological Survey (USGS). Hydrography, digital elevation models (DEMs), and land use and land cover data obtained from the Rhode Island Geographic Information System (RIGIS 1986) were then extracted for each watershed using ARC/INFO software (Environmental System Research Institute). The layers for hydrography were derived from 1:24,000-scale USGS topographic maps. The DEMs came from USGS digital elevation models and had a resolution of $30 \mathrm{~m}$. The data layer for land use and land cover (Table 2) was developed from 1995 aerial photography (1:24,000 scale) coded to Anderson-modified Level 3 to one-half-acre minimum polygon resolution (Anderson et al. 1976). The area of each land use category within each watershed was summed and divided by the total area of the watershed to determine its percentage of the watershed. 
Table 1 Physical descriptions of riparian sites ranging from low to high RLU

\begin{tabular}{|c|c|c|}
\hline Site & $\begin{array}{l}\text { Percent } \\
\text { RLU }\end{array}$ & Site description \\
\hline WR & 4 & $\begin{array}{l}\text { A 4th order, inland river in Richmond, RI, off a 2-lane highway in a heavily forested and shaded watershed- } \\
\text { protection area; it serves as the state's principal reference stream. }\end{array}$ \\
\hline $\mathrm{AB}$ & 12 & $\begin{array}{l}\text { A 4th order stream in Tiverton, RI, on the east side of Narragansett Bay, adjacent to a two-lane highway in a } \\
\text { heavily forested and shaded area; it serves as the state's reference coastal stream. }\end{array}$ \\
\hline $\mathrm{DB}$ & 17 & $\begin{array}{l}\text { A 1st order stream in Tiverton, RI, on the east side of Narragansett Bay, off a small residential road; it flows from a } \\
\text { wetland and is completely shaded by an extensive wooded riparian zone. }\end{array}$ \\
\hline AR & 24 & $\begin{array}{l}\text { A 2nd order stream in a N. Kingstown, RI, business/residential area, flows from a pond, under a two-lane road over } \\
\text { a fish ladder; the riparian zone is mostly shaded by an extensive wooded area heavily used by fishermen. }\end{array}$ \\
\hline $\mathrm{BB}$ & 29 & A 2nd order stream in a Warwick, RI, residential area; the riparian zone is well wooded and shades most of the stream. \\
\hline GB & 38 & $\begin{array}{l}\text { A 2nd order stream in a Warwick, RI, mixed commercial/residential area; flows from Gorton Pond, a local swimming } \\
\text { area, along a small road adjacent to a commercial development; it is shaded by a wooded riparian zone. }\end{array}$ \\
\hline TB & 53 & $\begin{array}{l}\text { A } 1 \text { st order stream in a Warwick, RI, commercial/residential area flowing from a pond adjacent to a four-lane } \\
\text { highway; riparian zone shades the stream but includes a wooded swamp that smells of petroleum; the brook is } \\
\text { heavily laden with trash. }\end{array}$ \\
\hline PB & 59 & $\begin{array}{l}\text { A } 1 \text { st order stream in a Warwick, RI, residential area, flows underground, then out from a culvert and runs a short } \\
\text { distance through a housing development into a salt marsh; the wooded riparian zone is very narrow, with } \\
\text { residences on either side and is only partly shaded. }\end{array}$ \\
\hline
\end{tabular}

We characterized the watersheds by the relative amounts of natural and human-altered land, which included all land use categories (Table 2). For purposes of comparison with other published studies, we calculated percent impervious surface (IS) for each watershed (Arnold and Gibbons 1996), but because we were focusing on residential development, the sites were characterized by low to high percent RLU (Table 3).
We conducted the surveys in stream reaches that were as close to $100-\mathrm{m}$ in length as possible, unless we were restricted by roads or total length of the stream. All reaches were coastal, located above tidal influence of the salt marshes, except for one inland site at the WR, which was included because it is the primary reference site for the state of Rhode Island wadeable stream surveys (RIDEM 2002). We walked each 100-m stream reach

Table 2 Definitions of land use categories developed from 1995 aerial photography (1:24,000 scale)

\begin{tabular}{|c|c|}
\hline Category & Definition \\
\hline Residential & Low ( $>2$ acre), medium ( $1 / 8$ acre to 2 acre), and high $(<1 / 8$ acre) density lots. \\
\hline IS & $\begin{array}{l}\text { Calculated from the fractions of commercial/industrial, infrastructure, and RLUs that are impervious (e.g. roofs, } \\
\text { parking lots, etc.). }\end{array}$ \\
\hline $\begin{array}{l}\text { Commercial/ } \\
\text { industrial }\end{array}$ & Sale of products and services, manufacturing, design, assembly, and mixed uses. \\
\hline Infrastructure & $\begin{array}{l}\text { Roads ( }>200 \mathrm{ft}) \text {, airports, railroads, water and sewage treatment, waste disposal (landfills, junkyards), power lines } \\
(>100 \mathrm{ft} \text { width), other transportation facilities, institutions (schools, hospitals, churches). }\end{array}$ \\
\hline Agriculture & $\begin{array}{l}\text { Pasture, cropland, orchards, groves, nurseries, cranberry bogs, confined feeding operations, and idle agriculture } \\
\text { (abandoned fields and orchards). }\end{array}$ \\
\hline Forest & Deciduous, evergreen, mixed forest, brushland (shrub and brush areas, reforestation). \\
\hline Wetland & $\begin{array}{l}\text { Emergent wetland (marsh/wet meadow, emergent fen or bog), scrub-shrub wetland (shrub swamp, shrub fen or } \\
\text { bog), forested wetland (coniferous, deciduous, dead). }\end{array}$ \\
\hline Open Area & $\begin{array}{l}\text { Vacant land, cemeteries, beaches (fresh and salt), sandy areas (not beaches), rock outcrops, mines, quarries, gravel } \\
\text { pits, transitional areas, and mixed barren areas. }\end{array}$ \\
\hline Water & Freshwater (ponds, lakes, streams). \\
\hline
\end{tabular}


Table 3 Land uses for coastal watersheds along a gradient of RLU

\begin{tabular}{|c|c|c|c|c|c|c|c|c|}
\hline Survey Sites & WR & $\mathrm{AB}$ & DB & AR & BB & GB & TB & PB \\
\hline Watershed area (acres) & 1,238 & 1,940 & 113 & 6 & 91 & 52 & 204 & 34 \\
\hline \multicolumn{9}{|c|}{ Anthropogenic land uses (percent) } \\
\hline Residential & 4 & 12 & 17 & 24 & 29 & 38 & 53 & 59 \\
\hline $\mathrm{IS}^{\mathrm{a}}$ & 1 & 3 & 3 & 8 & 43 & 27 & 47 & 30 \\
\hline Commercial/industrial & 0 & 0 & 0 & 2 & 7 & 8 & 17 & 6 \\
\hline Infrastructure & 1 & 2 & 1 & 4 & 37 & 14 & 23 & 6 \\
\hline Agriculture & 5 & 14 & 10 & 5 & 1 & 1 & 0 & 0 \\
\hline Recreational & 0 & 0 & 0 & 1 & 1 & 3 & 0 & 7 \\
\hline \multicolumn{9}{|c|}{ Natural land uses (percent) } \\
\hline Forest & 79 & 52 & 25 & 33 & 7 & 19 & 3 & 5 \\
\hline Wetland & 10 & 17 & 44 & 18 & 9 & 6 & 2 & 6 \\
\hline Open area & 0 & 2 & 2 & 8 & 4 & 6 & 0 & 6 \\
\hline Water & 2 & 0 & 1 & 5 & 4 & 6 & 1 & 4 \\
\hline 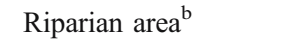 & 0.055 & 0.362 & 0.124 & 0.001 & 0.048 & 0.059 & 0.372 & 0.083 \\
\hline
\end{tabular}

${ }^{\text {a }}$ Percent IS is calculated from the fractions of commercial/industrial, infrastructure, and RLUs that are impervious (e.g. roofs, parking lots, etc.)

${ }^{\mathrm{b}}$ Percent riparian area is calculated as the area of contiguous forest around the stream reach divided by the area of the watershed.

with a measuring tape and marked the zero and $100-\mathrm{m}$ points. Stream reaches were delineated using 1:24,000 scale orthophotography and on-site latitude/longitude were established by using a Garmin-76 geographic positioning system calibrated to a permanent survey marker in Kingston, RI, for an accuracy of 1-3 m. All sites were located between $41^{\circ} 33^{\prime}$ and $41^{\circ} 42^{\prime}$ north latitude and $71^{\circ} 08^{\prime}$ and $71^{\circ} 43^{\prime}$ west longitude.

\section{Stream surveys}

In the spring of 2001, we investigated several sites to select, measure, and mark a representative stream reach for each watershed where replicate samples could be collected annually for a 3-year period (2001-2003). Reaches needed to be accessible, at least $100 \mathrm{~m}$ from roads and bridges to avoid influence from runoff, and contain riffle zones for sampling. Because some of these urbanized streams were close to roads, we opted to establish our stream reaches $100 \mathrm{~m}$ from any road, even if it forced some reaches to be shorter than $100 \mathrm{~m}$. As a result, only four of the initial seven reaches were $100 \mathrm{~m}$ long [Buckeye Brook (BB), Donovan Brook (DB), Gorton Brook (GB), WR]; two were 75 m [Annaquatucket River (AR), Tuscatucket Brook (TB)], and one was $36 \mathrm{~m}$ [Passeonkquis Brook (PB)] (Table 1). In 2002, an eighth reach of $100 \mathrm{~m}$ was added (AB) because it is a Rhode Island state reference site for coastal streams and it provided another low-RLU site for our study.

\section{Physicochemical}

Physicochemical parameters were measured at all sites on the same two occasions, at the beginning and at the end of our macroinvertebrate sampling period in July and August each year. During the first year's sampling, we also took measurements on the day when benthic invertebrates were sampled. At each site we measured temperature, dissolved oxygen (DO), $\mathrm{pH}$, conductivity, and stream flow, width, and depth. We measured temperature and DO by using YSI Model 85, and $\mathrm{pH}$ and conductivity by using a Hannah Multiparameter meter. We measured stream flow for each replicate site just above the each stream's substrate within the sampling riffle, with a Streamflow ${ }^{\circledR}$ portable flow meter and depth with a meter stick. This procedure was followed for the entire 3-year survey period.

\section{Habitat}

The structure of instream and riparian habitat was assessed annually by evaluating the variety and quality of the substrate, channel morphology, bank structure, and riparian vegetation according to the RBP, and a habitat assessment score was calculated (Barbour et al. 1999). Habitats for each site were assessed on the same day that benthic macroinvertebrates were sampled by using the RBP Habitat-Assessment Field-Data Sheet for high gradient streams to score each habitat parameter 
using consensus-based, best professional judgment of the investigators. Bank stability, instream features, and riparian zones were photographed with a digital camera for the habitat record.

To further characterize vegetation throughout the riparian zone, we conducted intensive surveys (in 2002 only) of the riparian vegetation (trees, shrubs, and herbaceous plants) at each site by establishing transects perpendicular to the stream reaches and $20 \mathrm{~m}$ out from stream banks (Lussier et al. 2006).

\section{Nutrients}

We measured ammonia, nitrate, nitrite, and phosphate on the same 2 days as the chemical metrics, at the beginning and end of the annual macroinvertebrate sampling periods. Water samples were filtered in the field, transported on ice, and frozen until analysis. Dissolved nitrate, nitrite, and ammonia were measured on a Lachat Instruments QuikChem 8000 FIA+ automated ion analyzer and expressed as $\mu \mathrm{M}$ N/L. Determination of ammonia was based on the Berthelot reaction (Diamond 1997a) and total dissolved inorganic nitrogen (DIN) concentrations were calculated from nitrate and nitrite measurements (Diamond 1997b; Schroeder 1997), and ammonia. Phosphorus was determined by flow injection analysis colorimetry using QuikChem Method 31-115-01-3-A for Lachat Instruments (Huberty and Diamond 1998).

\section{Biological}

Streams were sampled according to the RBP (Barbour et al. 1999), with some modifications. Rather than using a standard kick net over an area of approximately $1 \mathrm{~m}^{2}$ to take a single qualitative sample of benthic macroinvertebrates, we used a Hess sampler to take multiple quantitative samples (each with $0.1-\mathrm{m}^{2}$ area) with a net of 500- $\mu \mathrm{m}$ mesh (ASTM 2000a, b; Hellawell 1978). The Hess sampler enabled us to obtain the most quantitative and consistent samples possible using a Hess sampler in riffles, which are reported to have the highest invertebrate biomass (Rosenfeld and Hudson 1997). The single habitat approach, used in the state of Rhode Island wadeable stream (RBP) surveys, is a means of standardizing assessments among streams with cobble substrates having riffles or runs. These habitats are known to support the highest diversity and abundance of benthic 


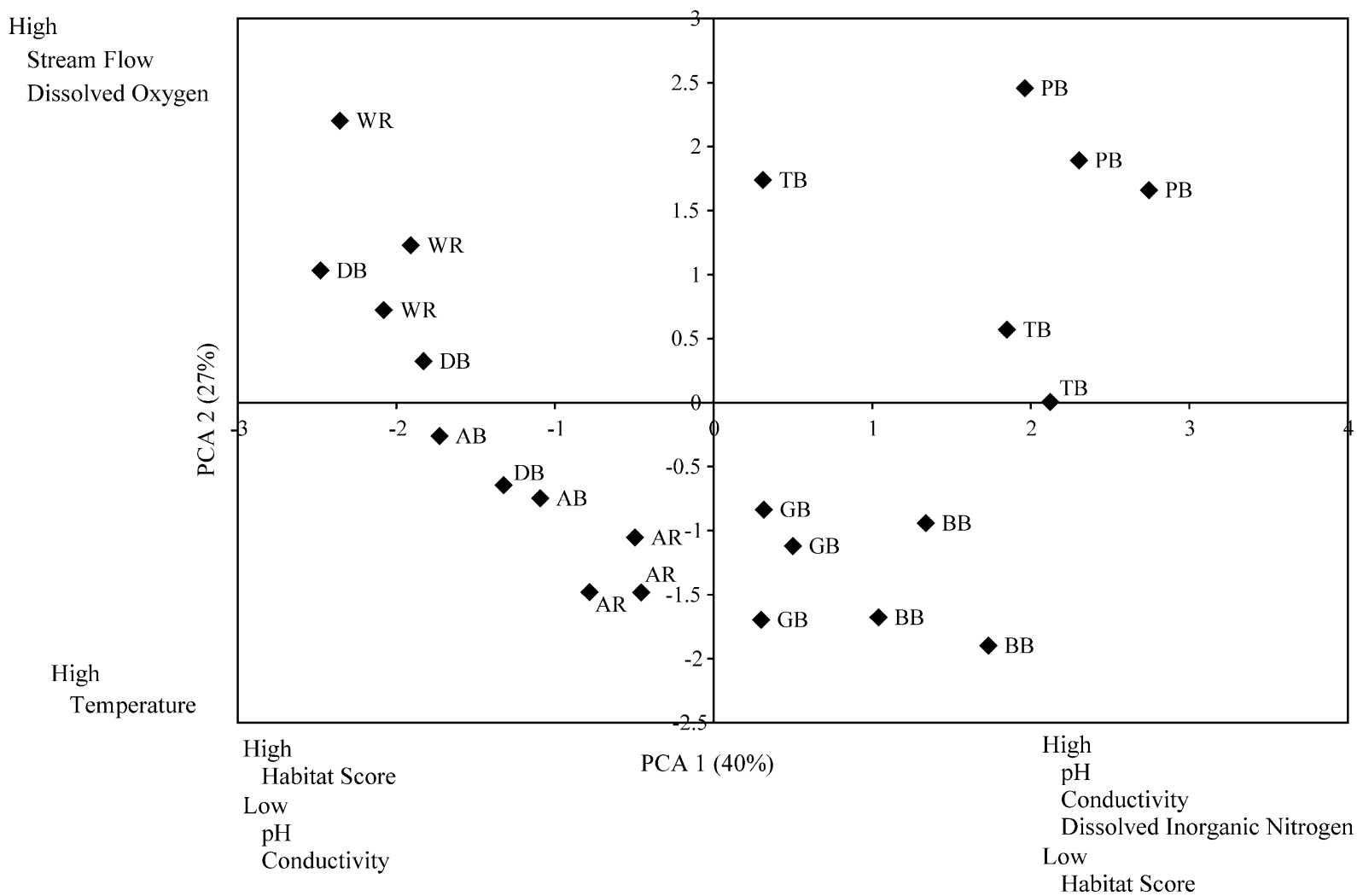

Fig. 2 PCA for physicochemical data: PC1 included pH, conductivity, DIN, and habitat ( $X$ axis); PC2 included flow, DO, and temperature (Y axis)

invertebrates and provide a representative sample of the stream reach (Barbour et al. 1999). Single-habitat sampling has been shown to be effective at detecting habitat disturbance while controlling for natural variation among stream sites (Hewlett 2000; Parsons and Norris 1996; Roy et al. 2003). Riffle assemblages have also been shown to exhibit strong correlations with environmental variables, both physical and chemical, that result from land cover change (Roy et al. 2003).

In 2001, with no preliminary biological data from our selected sites, we designed our sampling regime to differentiate impaired and unimpaired sites by taking as many samples from each reach as time allowed with our available staff. Starting at the downstream end of a reach, we collected two samples (one in faster flow and one in slower flow, as measured just above the substrate) from each of five randomly chosen riffles per reach, which allowed us to differentiate the sites statistically (Resh 1979; Resh and McElravy 1993; Resh et al. 1995) During sampling, the substrate was disturbed to a depth of 3 to 4 in for a 3 -min period and rocks were brushed clean to collect attached organisms. To better discriminate differences among the sites, we kept the samples separate rather than compositing them. Samples were preserved in $95 \%$ ethanol.

Samples were collected from all sites during the RBP seasonal index period (July and August) in as few days as possible, but never within 3 days following a significant rain event, defined as greater than 0.2 in of precipitation. For our 2001 sampling regime, at least 300 organisms per sample were

Table 5 PCA principal components 1 and 2 for physicochemical parameters

\begin{tabular}{lrr}
\hline Principal components & \multicolumn{1}{l}{ PC 1 } & \multicolumn{1}{c}{ PC 2 } \\
\hline Flow & -0.121739 & 0.370200 \\
Temperature & 0.065726 & -0.593836 \\
DO & -0.121614 & 0.561592 \\
Conductivity & 0.555165 & -0.122088 \\
PH & 0.302256 & -0.174762 \\
DIN & 0.513528 & 0.345340 \\
Habitat & -0.550266 & -0.173835 \\
\hline
\end{tabular}




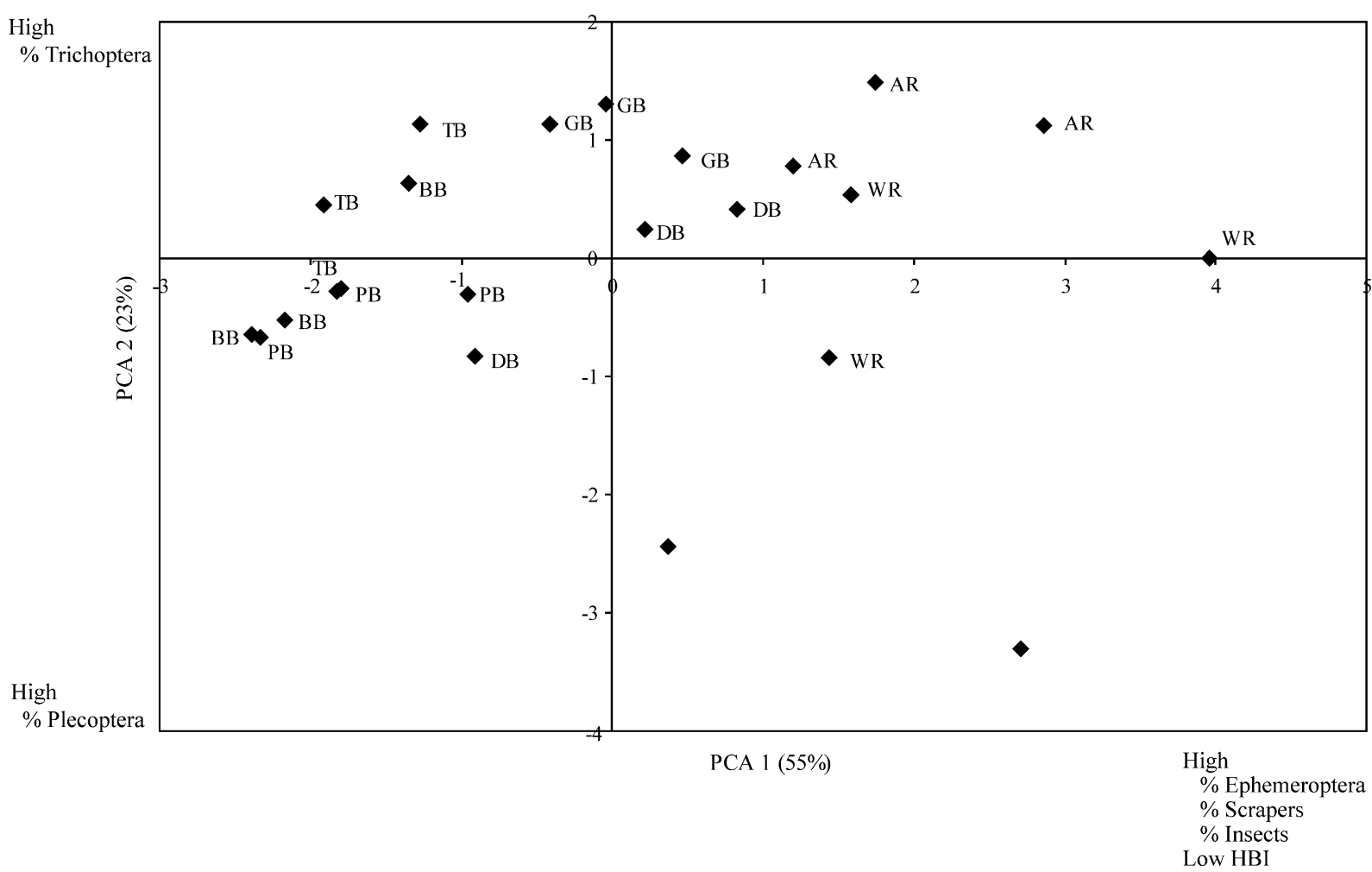

Fig. 3 PCA for biological data: PC1 included percent Ephemeroptera, percent Scrapers, percent Insects, and HBI ( $X$ axis); PC2 included percent Trichoptera and percent Plecoptera ( $Y$ axis)

selected by using a random grid, and then identified taxonomically to genus level by using peer-reviewed taxonomic keys (Klemm et al. 2002).

In 2002, our sampling program expanded to include detailed assessment of riparian vegetation in preparation for breeding bird surveys the following year (Lussier et al. 2006). Because of these additional activities, we needed to more efficiently sample the benthic macroinvertebrates. In 2002 and 2003, we altered our sampling method by intensively sampling one riffle in each stream reach, collecting three samples per riffle (downstream, middle, and upstream) (Karr and Chu 1999; Kerans and Karr 1992). Samples were preserved in $95 \%$ ethanol. The samples were kept separate and each sample counted entirely and taxonomically identified to at least genus level.

Data analyses

\section{Hilsenhoff biotic index}

Preliminary statistics were calculated according to the RBP 2nd edition (Barbour et al. 1999). Organism counts were compiled into taxonomic categories and the Hilsenhoff biotic index (HBI) was calculated (Hilsenhoff 1987). Numerical data were further analyzed per annum and per site for physicochemical, habitat, and biological metrics. Samples were kept separate for data analysis. In order to compare biological data for all 3 years, given the change in biological sampling method, biological metrics were based only on metrics for which we could calculate a percentage of the sample.

Table 6 PCA principal components 1 and 2 for biological parameters

\begin{tabular}{lrr}
\hline Principal components & \multicolumn{1}{l}{ PC 1 } & \multicolumn{1}{l}{ PC 2 } \\
\hline HBI & -0.492568 & 0.016432 \\
Ephemeroptera (\%) & 0.494620 & 0.046685 \\
Plecoptera (\%) & 0.231749 & -0.696202 \\
Trichoptera (\%) & 0.186465 & 0.686981 \\
Scrapers (\%) & 0.424023 & 0.170295 \\
Insects (\%) & 0.494424 & -0.109137 \\
\hline
\end{tabular}




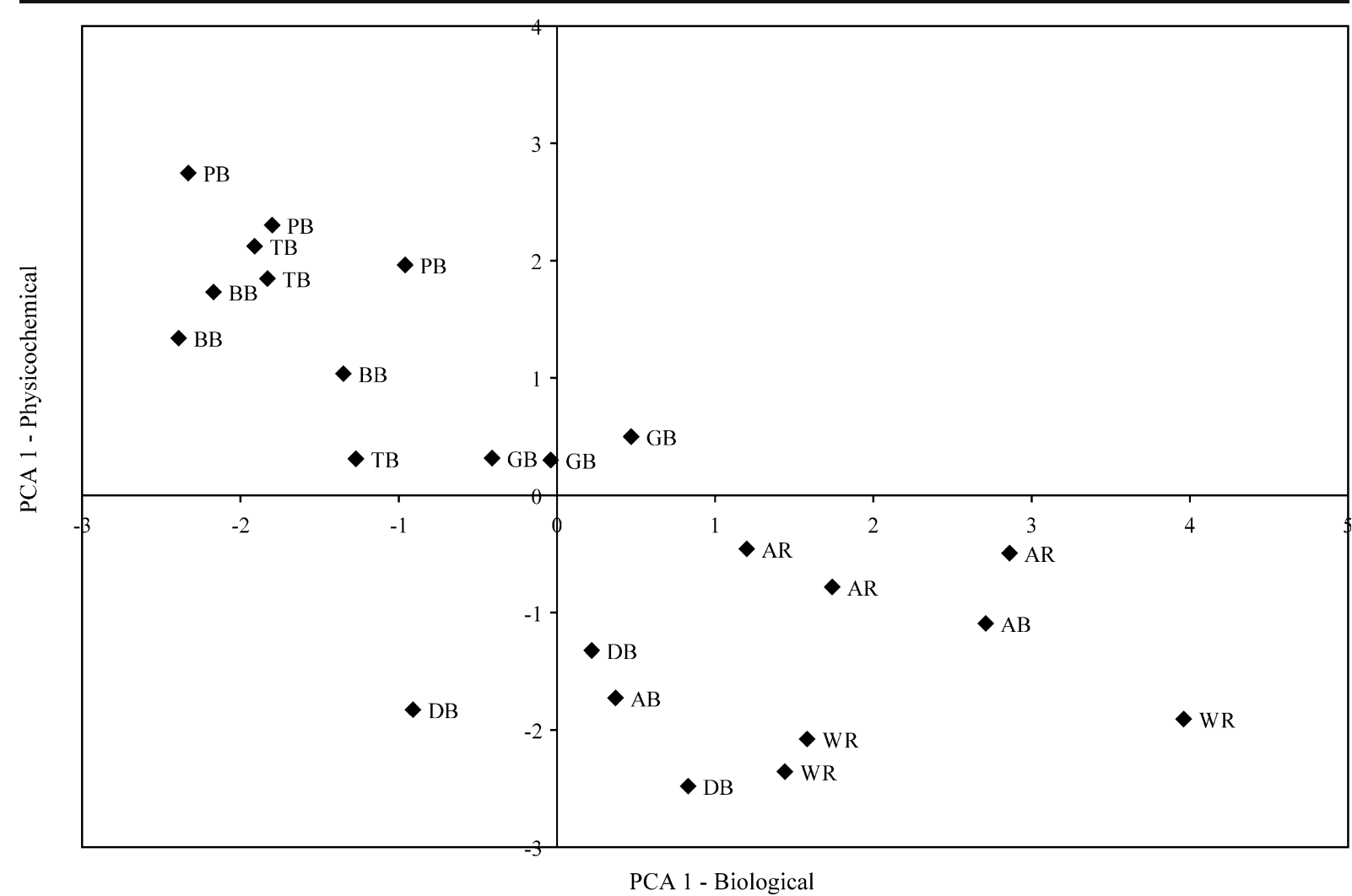

Fig. 4 PCA shows the relationship between biological and physical parameters: PC1 physicochemical versus PC1 biological parameters

\section{Principal component analyses}

We conducted principal component analyses (PCA) to determine which metrics contributed most to the variability in each data category, i.e. physicochemical and biological (Morrison 2005). We ran separate PCAs with annual mean values for physicochemical (flow, temperature, DO, conductivity, $\mathrm{pH}, \mathrm{DIN}$, and habitat-assessment scores) and biological measurements (percent Ephemeroptera, percent Plecoptera, percent Trichoptera, percent Scrapers, percent Insects, and HBI score). First and second principal components were compared among all sites and first principal components were compared with percent RLU to determine correlation coefficients.

\section{Regression analyses}

Linear regressions were used to compare RLU with IS at our sites, and to correlate percent RLU with habitat-assessment scores, nutrient results, and selected landscape metrics. Coefficients of variation $\left(R^{2}\right)$ and $P$ values were computed according to Zar (1999).

\section{Results}

Physicochemical and habitat

As percent RLU increased, conductivity increased significantly $\left(R^{2}=0.82, P=2.133 \mathrm{E}-03\right)$. TB and $\mathrm{PB}$, with $53 \%$ and $59 \%$ RLU, respectively, had among the lowest habitat-assessment scores (139 and 97, respectively) and also some of the highest values for conductivity $(289 \mu \mathrm{S}$ and $266 \mu \mathrm{S}$, respectively) (Table 4). However, BB, with a lower percent RLU $(29 \%)$ also had a high conductivity value $(268 \mu \mathrm{S})$; and GB, with higher percent RLU (38\%) than BB, had a higher habitat assessment score (160) than BB (135).

Principal component scores for each site/year combination were derived using the physiochemical variables (Fig. 2). Principal component 1 (X axis) accounts for $40 \%$ of the variability and represents a gradient of stations with high habitat-assessment scores, low $\mathrm{pH}$ and low conductivity to stations with high $\mathrm{pH}$, high conductivity, high DIN, and low habitat-assessment scores (Table 5). Principal component 2 (Y axis) accounts for $27 \%$ of the variability and organizes the 


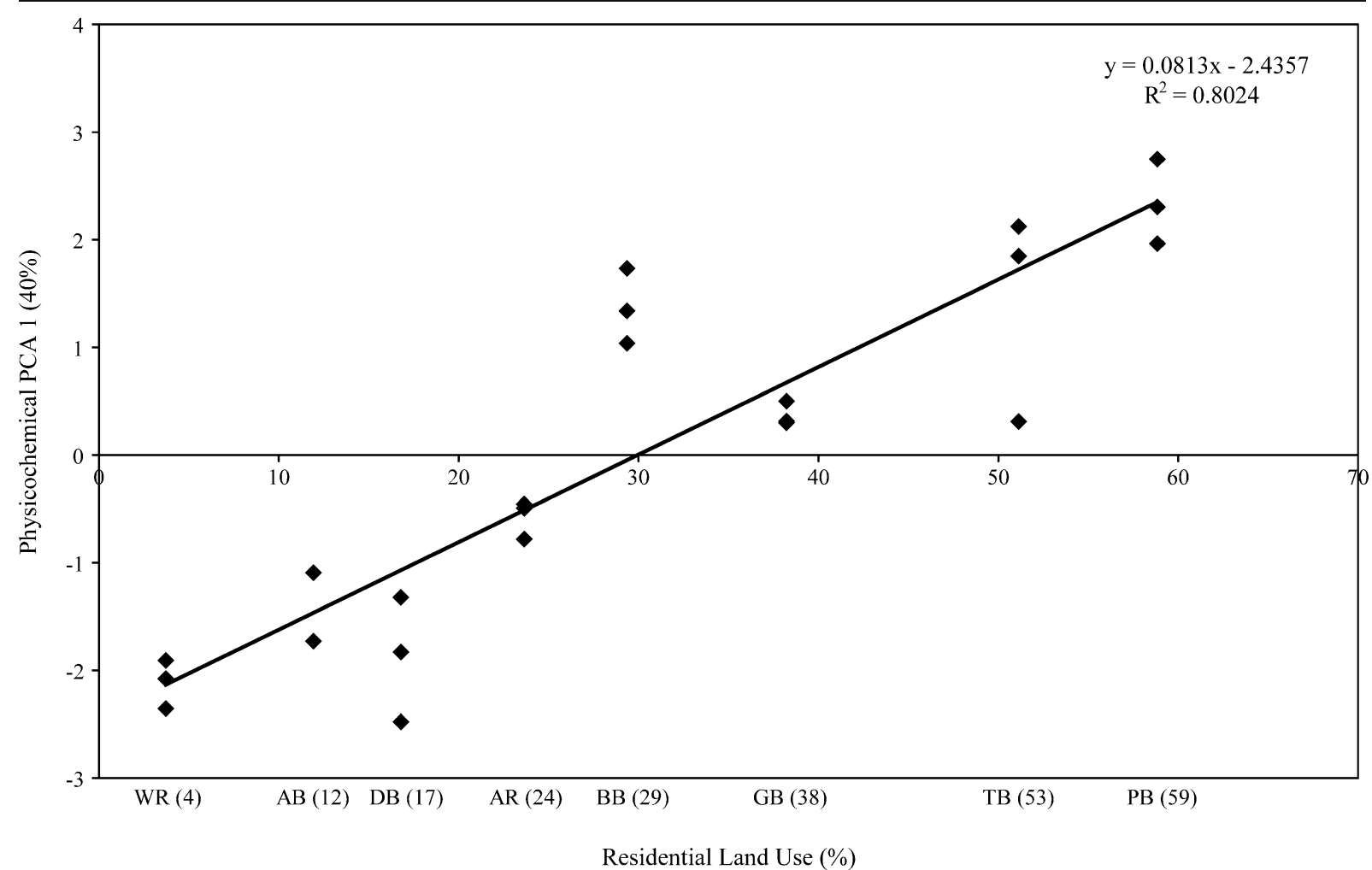

Fig. 5 PCA for physicochemical data versus percent RLU at the stream sites

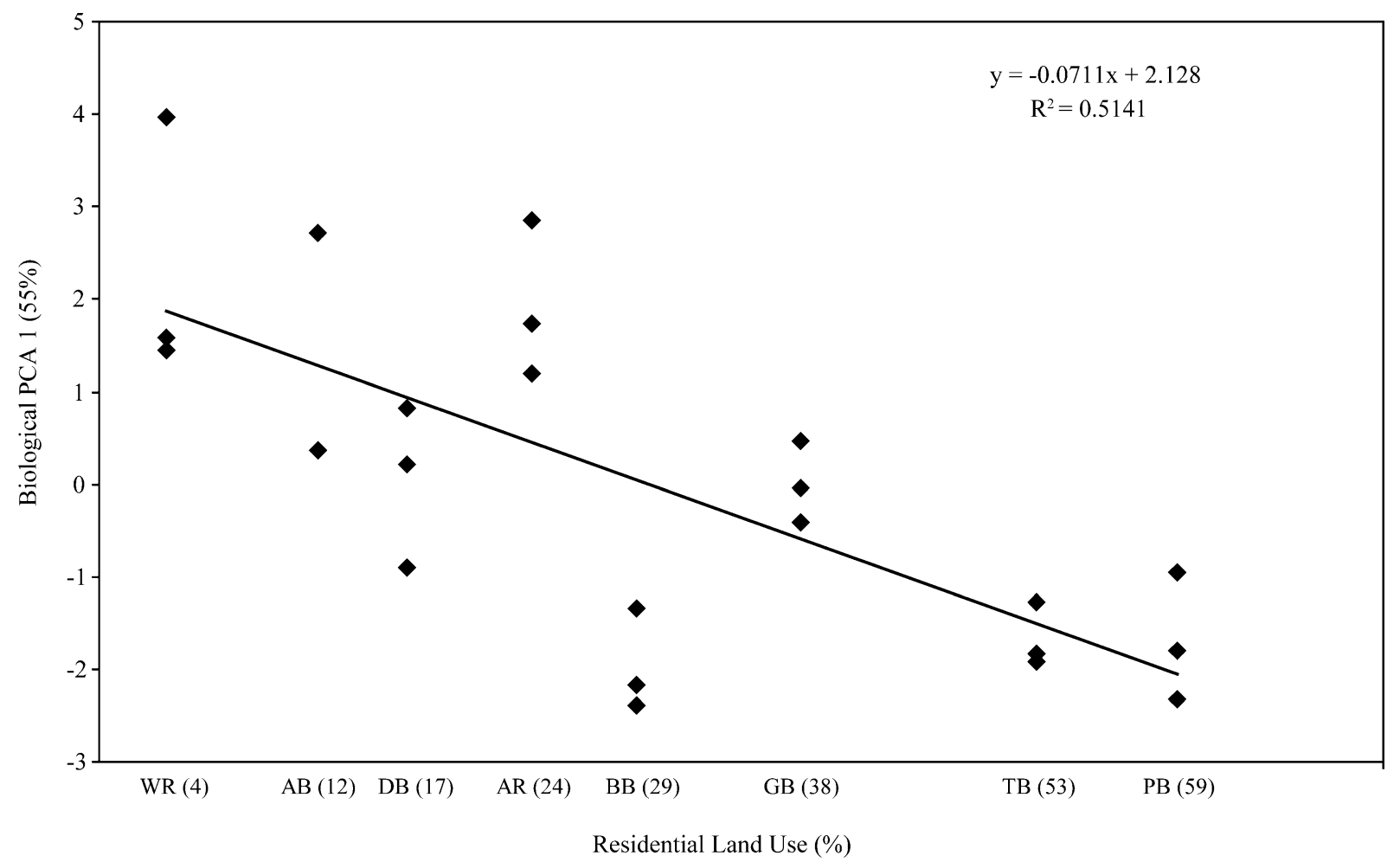

Fig. 6 PCA for biological data versus percent RLU at the stream sites 


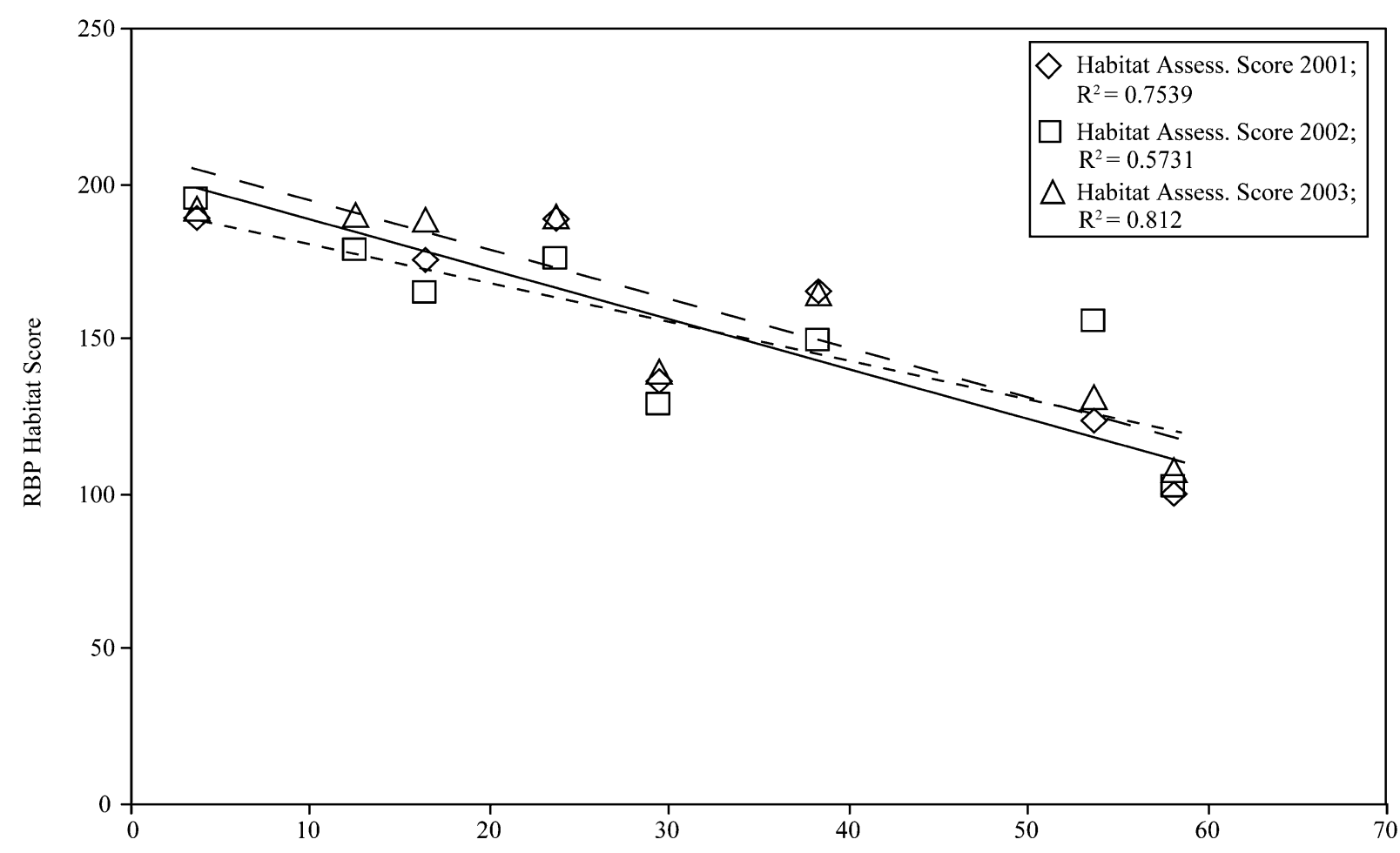

Percent Residential Land Use
Fig. 7 Regression analysis of RBP habitat assessment scores for 3 years versus percent RLU

sites based upon stream flow, DO, and temperature. Values for each of the 3 years were tightly clustered for all except DB and TB, both of which had higher variability in flow rate than the other sites (Table 4). Sites with RLU $<17 \%$ (WR, AB, DB) were clustered in the left quadrants that had higher stream flow, DO, and habitat-assessment scores. Sites with percent RLU $>29 \%$ (BB, GB, TB, PB) clustered in the right quadrants with higher $\mathrm{pH}$, conductivity, and DIN.

\section{Biological}

Biological variables were used to derive the principal component scores for each site/year combination (Fig. 3). Principal component 1 (X axis) accounts for $55 \%$ of the variability and represents a gradient from low to high of the percent Ephemeroptera, percent Scrapers, percent Insects, and HBI (Table 6). Only three sites: AR (24\% RLU), WR (4\% RLU), and Adamsville River (12\% RLU) had a predominance of the more sensitive taxa (Ephemeroptera, Scrapers, and Insects) and low HBI.

Principal component 2 (Y axis) accounts for 23\% of the variability and is primarily a contrast separating stations based upon percent Trichoptera and percent Plecoptera. Most of our sites had high percentages of Trichoptera.

Comparison of biological with physicochemical and habitat metrics

The relationship between biological variables ( $\mathrm{X}$ axis) and physicochemical variables (Y axis) for each site/year combination, was demonstrated by plotting the principal component 1 scores (Fig. 4). There is a cluster of sites with low percent RLU and higher habitat and physicochemical results (lower right quadrant), versus sites with higher percent RLU and the lower physicochemical and habitat-assessment scores (upper left quadrant) illustrating the interrelationship among these parameters.

Land use

Physicochemical parameters were strongly correlated with percent RLU at the stream sites. Figure 5 shows a significant correlation between the Principal Component 1 scores (lower scores being better) and percent RLU ( $P=1.79245 \mathrm{E}-05)$. The WR site (at 4\% 


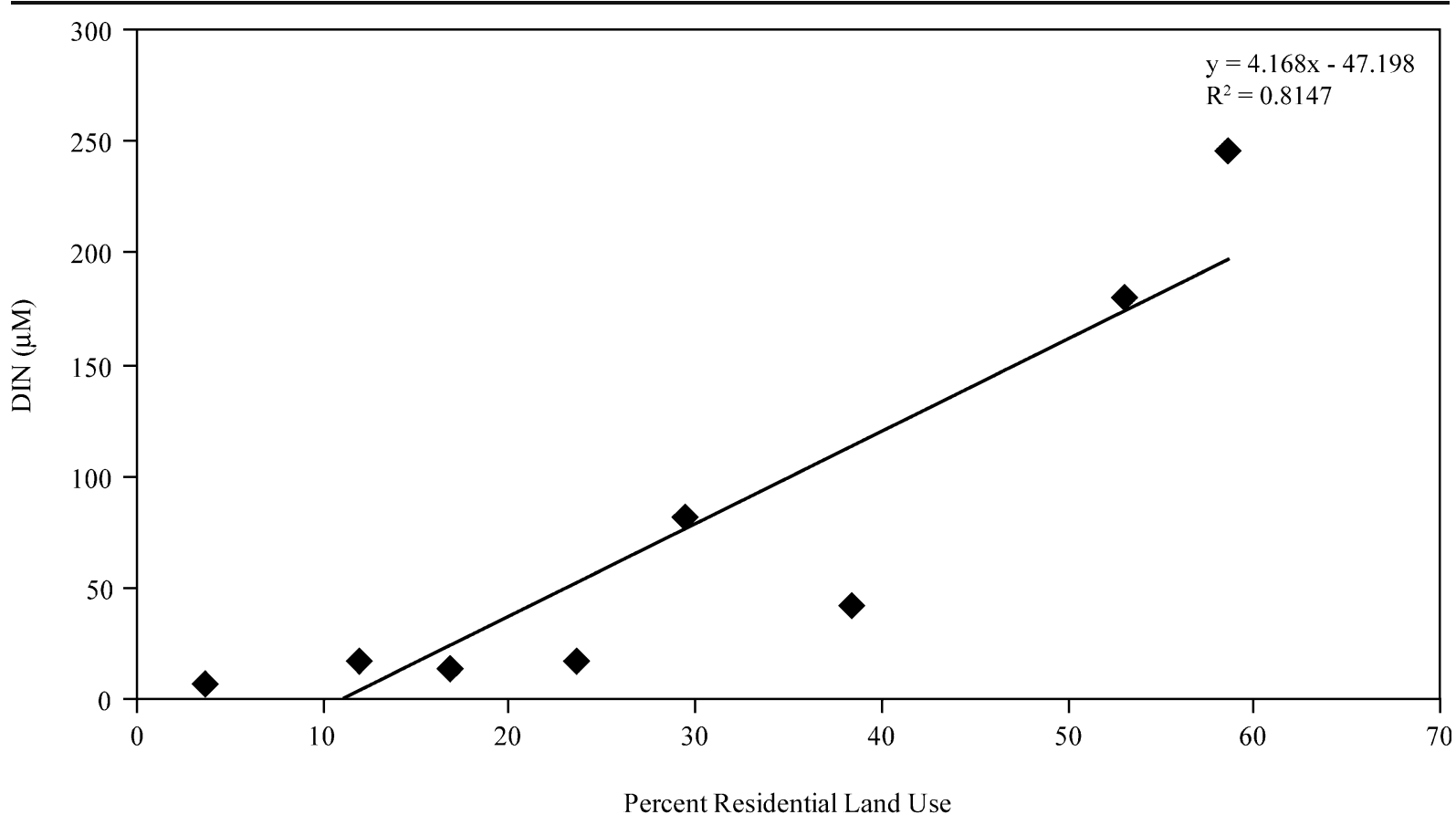

Fig. 8 Regression analysis for DIN versus percent RLU at all study sites

RLU) showed the best physicochemical results (high $\mathrm{DO}$, high flow rate, and low temperature). Adamsville River and DB, with 12 and $17 \%$ RLU, respectively, had slightly less optimal values, but all three of these lower percent RLU sites had low conductivity and high habitat-assessment scores, both of which are indicators of good stream quality. The lowest habitat-assessment scores (indicating degraded condition) occurred at sites with the highest percent RLU.

There was a significant negative correlation $(P=$ 1.18182 E-04) between percent RLU and the principal component 1 scores for biological parameters at the stream sites (Fig. 6). The lowest biological scores are at the highest percent RLU sites (lower right quadrant).

The natural vegetation cover for all of our sites was deciduous forest and wetland, both of which decreased significantly with increasing percent RLU (Lussier et al. 2006). However the sum of these two land use categories (percent forest plus percent wetland) were much more strongly negatively correlated with both percent RLU and percent IS $(P=1.11$ E-03 and $P=4.01$ E-04, respectively; data not shown). Percent IS was positively correlated with percent RLU among our stream sites $\left(R^{2}=0.64\right.$, data not shown). The higher percentage of IS in sites BB $(93 \%$
IS) and TB (47\% IS) reflects the higher percentages of land use categorized as infrastructure at those sites (Table 3).

\section{Habitat}

Habitat-assessment scores, calculated annually according to Barbour et al. (1999), were compared directly to percent RLU and were negatively correlated $(P=$ 3.178 E-03) showing a gradual decline of instream and stream-bank habitat with increasing residential development (Fig. 7).

\section{Nutrients}

Results show that only the $\mathrm{AB}$ site had high levels of phosphate $(2.1 \mu \mathrm{M})$, only the BB site had high levels of nitrite $(4 \mu \mathrm{M})$, and only the TB site had high levels of ammonia $(16.2 \mu \mathrm{M})$ (Table 4). However, there were significant increases in nitrate $\left(R^{2}=0.80, P=8.99\right.$ E-09) and corresponding DIN $\left(R^{2}=0.81, P=2.143 \mathrm{E}-03\right)$ with increasing percent RLU across all sites (Fig. 8). Sites DB and TB had extremely high ammonia, with 3 -year means of 8.3 and $16.2 \mu \mathrm{M}$, respectively. Sites TB and PB had extremely high nitrate, with 3-year means 162.6 and $241.1 \mu \mathrm{M}$, respectively. 


\section{Discussion}

Physicochemical and habitat

Streams from watersheds with greater than $24 \%$ RLU exhibited some of the elements of "urban stream syndrome," described by Meyer et al. (2005) as a pattern of physicochemical degradation including flashiness, elevated nutrients and contaminants, and altered channel morphology and stability associated with urban land use. With increasing urbanization, degraded physical condition at our sites was reflected in elevated nutrients, lower habitat-assessment scores (indicating altered channel morphology and stability), and increased conductivity (indicating increased organic matter) (Table 4). There was a strong correlation between physicochemical parameters and percent RLU (Fig. 5, Table 4), but PCA did not reveal any particular physicochemical attributes driving the lower habitat-assessment scores (Fig. 2); all of the physicochemical parameters we measured contributed to stream condition (Table 5). In a study of New England Coastal basins, Campo et al. (2003) found that specific conductance, $\mathrm{pH}$, total nitrogen, and total phosphorus in streams all increased with increasing urbanization in the watershed. A study of New Hampshire streams similarly indicated that an interaction of effects of urbanization contributed to stream degradation (Deacon et al. 2005).

Slightly more variable habitat-assessment scores for DB (17\% RLU) and TB (53\% RLU) over the 3year-sampling period might be related to their status as 1st order streams, which lack flow contributions from tributaries (Fig. 7). Although they were perennial streams, their flow rates were more variable than higher order streams (Table 4). The DB stream originated from a wooded swamp, which is reflected in the high percentage of wetland in its watershed (Table 3), and could also contribute to its low $\mathrm{pH}$ (Wetzel 1975).

Walsh et al. (2005) discussed the covariance of urban stressors and the importance of urban stormwater runoff and deforestation as primary drivers of "urban stream syndrome." Polluted storm-water runoff can also contribute to degraded water quality and aquatic habitat in streams (Hudak and Banks 2006). A forested riparian zone helps to reduce runoff, maintain stable flows, and provide habitat, while urbanization increases the amount of IS and increases watershed runoff (Wang et al. 1997). We observed storm-water runoff at all of our higher RLU sites that also had degraded riparian habitat.

\section{Nutrients}

Nutrient measurements at our sites were associated with particular land uses in the watershed, not only RLU. For example, high phosphate was detected at $\mathrm{AB}$, which had $14 \%$ agricultural land use in the watershed, the highest of all our sites, and at DB, which had the second highest agricultural land use at $10 \%$ (Table 3). Omernik et al. (1981) found that the amount of agricultural area in a watershed was related to the concentrations of nitrogen and phosphorus in the streams. Our phosphate measurements were not correlated with percent RLU, but only occurred at sites with higher agricultural land use.

Another example of distinctive nutrient levels was the BB site, which was the only site with high levels of nitrite. This site also had a very high organic load, shown by its high conductivity, coupled with extremely low flow rate (Table 4). This muddy, poorly flushed system also received drainage flow from an adjacent residential development and from a nearby airport. These conditions might have contributed to the high concentration of nitrite (Durborow et al. 1997).

Ammonia concentrations were highest at the DB, $\mathrm{BB}$, and TB sites $(8.3 \mu \mathrm{M}, 7.2 \mu \mathrm{M}$, and $16.2 \mu \mathrm{M}$, respectively), and seemed to be related to conditions that were unique to those sites. DB is a 1 st order stream with $44 \%$ wetland in the watershed and low $\mathrm{pH}$. The high level of breakdown of leaves and other organic materials could elevate the ammonia concentration, at least in the first few hundred meters of a stream; our samples were taken between 100 and $200 \mathrm{~m}$ from the stream origin (Peterson et al. 2001). $\mathrm{TB}$, another 1st order stream, is adjacent to a residential area with old septic systems subject to leakage. At that site we observed oil slicks on pools of water in the adjoining wetland, which lent evidence that it was saturated, possibly compromising its ability to function as a filter for the stream. Both BB and TB had the highest percent IS and percent infrastructure of any sites, making them more susceptible to contaminated runoff.

Nitrate was strongly correlated with percent RLU at our sites and was the main contributor to the strongly significant correlation between DIN and 
percent RLU (Fig. 8). Vitousek et al. (1997) found that with increasing human disturbance, stream nitrogen contains a higher proportion of nitrate, which is correlated with human population density. With increasing development, wetlands and riparian areas that act as natural nitrogen traps, are often lost or reduced in size to the point of minimal function.

\section{Biological}

In our study, the two lowest RLU sites, WR and $A B$ ( $4 \%$ and $12 \%$, respectively), reflected the best biological condition with high percentages of Ephemeroptera, scrapers, and insects and low HBI (Fig. 4), which are all indicators of good water quality (Barbour et al. 1999). Although we were unable to compare all of the biological metrics recommended in the RBP because of modifications to our sampling methods, the metrics we used (percent Ephemeroptera, percent Scrapers, percent Insects, percent Plecoptera, percent Trichoptera and HBI) included sensitive and insensitive taxa and a biotic index, which worked well with single-riffle sampling and allowed us to compare all 3 years of data.

Interestingly, our third lowest RLU site, DB (17\% RLU), showed a biotic composition similar to higherRLU sites AR and GB (24\% and 38\% RLU, respectively), possibly because $\mathrm{DB}$ is a first order stream with high ammonia and low $\mathrm{pH}$, characteristic of its origin from a freshwater swamp (Wetzel 1975).

Other studies have found increased insensitive taxa in headwater streams of watersheds with high levels of human influence (Megan et al. 2006; Moore and Palmer 2005). While AR and GB had intermediate biotic composition, the $\mathrm{BB}$ site (29\% RLU), had a biotic assemblage similar to that at sites with higher percent RLU. We suspected that the high relative abundance of the more tolerant Tricoptera at BB was a result of a high organic load and fine-sediment substrate associated with low DO (Table 4). Biologically, BB showed the same low diversity as sites TB (53\% RLU) and PB (59\% RLU), comparable to the findings of Chu and Karr (2001) who found low biodiversity below wastewater treatment plants. While our sites were not below wastewater treatment plants, they were located in densely populated watersheds with many older homes that have individual sewage disposal systems. The biotic composition at those sites almost entirely lacked sensitive macro- invertebrate taxa such as Ephemeroptera and insect larvae. Other studies have found similar biological impairment in urban streams such as reduced taxa diversity (Pratt et al. 1981) and lower index of biotic integrity scores (Steedman 1988) and species richness (Benke et al. 1981). Jones and Clark (1987) found that urbanization reduced diversity by reducing density of pollution-intolerant taxonomic orders and increasing pollution-tolerant orders. Walsh et al. (2005) stated that streams draining urban areas are commonly deficient in pollution-sensitive benthic macroinvertebrate species.

PCA also shows the relative biological variability among the 3 years of sampling data (Fig. 4). The sites (WR, AB, DB, and AR) with lower percent RLU (4 to $24 \%$ ) were more variable among years, possibly because of their higher biotic diversity. Sites with $>24 \%$ RLU had fewer total organisms representing fewer taxonomic families. Although we had suspected that stream flow may have affected biodiversity, especially with 1st-order streams (TB, DB, PB), we found that flow was actually more variable in $A B$, a 4th-order stream, and not very variable in $P B$ (Table 4). All of the streams had permanent flow except for the drought year of 2002, when AB (4th order) and DB (1st order) went dry after our sampling was completed. We found no relationship between stream flow and biodiversity.

\section{Watersheds as integrators}

Various indicators of biological integrity are used to measure ecosystem condition and have been correlated with the extent of land use at local, reach, and regional scales. Several New England stream studies corroborate our findings that increasingly urbanized watersheds can negatively affect water quality and benthic macroinvertebrate diversity (Coles et al. 2004; Campo et al. 2003; Deacon et al. 2005; Urban et al. 2006). Omernik et al. (1981) found that stream nitrate and phosphorus concentrations were strongly related to watershed-scale land use, but not to local land use near the stream. Osborne and Wiley (1988) found that riparian land uses nearest to the stream were most closely related to instream nutrient concentrations, but their sites had more agricultural land use throughout the watersheds. Many authors have considered a naturally vegetated watershed to be critical to the biological integrity of river ecosystems (Gregory et al. 
1991; Naiman 1992; Sweeney 1992). Other studies have shown that watershed-scale land cover is more important than reach-scale in driving the quality of habitat and biotic integrity in streams (Allan 2004; Potter et al. 2005; Roth et al. 1996; Roy et al. 2005; Wang et al. 1997). McBride and Booth (2005) found that forested urban lands with low IS moderate the impact of urbanization on streams. For our small streams, RLU at the watershed scale was a strong indicator of habitat condition, which in turn reflected physicochemical and biological integrity.

\section{Thresholds of RLU}

Several studies have found relationships between urban land cover (ULC), percent IS, and stream biota, concluding that levels as low as $8-10 \%$ ULC or IS result in altered macroinvertebrate communities (Wheeler et al. 2005). Stress-tolerant species replace sensitive species as ULC approaches 10\%, above which a new stable state is reached comprised of intolerant species. Wheeler et al. (2005) state that $10 \%$ ULC is characteristic of areas typically considered suburban. But Morley and Karr (2002) contend that impervious area alone cannot adequately capture all aspects of urbanization, and that streams may be degraded well below $10 \%$ imperviousness. They found strongly declining biological condition in streams as the percentage of ULC in the watershed increased. da Silva (2003) analyzed assessment data from 41 Rhode Island streams sampled from 1991 to 2001 using the RBP and found declining stream health at thresholds as low as $5 \%$ IS at the watershed scale. At our sites, percent IS was positively correlated with percent RLU, and results are consistent with these other studies. Data from our sites suggests a shift in species composition to a predominance of tolerant taxa in the range of 8 $47 \%$ IS (24-59\% RLU).

The results from these studies indicate that watersheds with low residential development, undisturbed riparian zones, minimal IS, and maximum forest cover, may be best able to sustain highly diverse stream biota. An example of this is our AR site: at $24 \%$ RLU and $8 \%$ IS, the watershed also has $33 \%$ forest cover, which is in the range of the sites with low percent RLU (Table 3). Although this site is intermediate in percent RLU and percent IS among our study sites, the physicochemical data show that it's more comparable with sites that have low percent
RLU and percent IS. Specifically, it has low DIN and a high habitat assessment score (Table 4). The major difference between this site and other medium percent RLU sites (BB and GB) is the high percent forest in the watershed. Roy et al. (2005) emphasized the importance of the amount of forest at the watershed scale to increased aquatic diversity in streams. In another study of coastal New England streams, Coles et al. (2004) found that developed and forested land cover were strongly correlated, responding inversely because the two variables were mutually exclusive.

For our sites, the combined land use category of percent forest plus percent wetland was negatively correlated with percent RLU and percent IS and could serve as a measure of stream condition. Biologically, AR has a diverse species composition which includes Trichoptera and also more sensitive taxa such as Ephemeroptera, scrapers, and insects (Fig. 4) similar to lower percent RLU sites (WR and DB), lending evidence to support the importance of higher percent forest in watersheds. One could make a similar comparison between $\mathrm{BB}$ and GB $(29 \%$ RLU and $7 \%$ forest vs. $38 \%$ RLU and $19 \%$ forest, respectively). Even with higher percent RLU, GB has lower conductivity and nutrients, and a higher habitat score than BB. However, GB also has lower percentages of IS and of infrastructure, which may contribute to a higher species composition than $\mathrm{BB}$, and demonstrate the importance of examining all of the land use categories within a watershed.

\section{Conclusions}

We investigated the relationship of RLU at the watershed scale with the biotic integrity of coastal streams by measuring physicochemical, biological, and habitat parameters at the local scale. PCA revealed a strong relationship between percent RLU and the physicochemical measurements and habitatassessment scores. The variables that were most responsive to percent RLU were conductivity, instream habitat, nitrate, and DIN.

The biological indicators we used indicated a shift in biotic composition from sensitive to insensitive taxa as percent RLU increased. Although this suite of indicators may not be sensitive enough to identify specific stressors at a stream site, it showed the overall detrimental effects of increasing urbanization on stream 
biota. The biological variables that were most responsive to percent RLU were percent Ephemeroptera, percent Scrapers, percent Insects, and HBI.

Sampling nutrients (DIN, nitrate, nitrite, ammonia, and phosphate) was a valuable addition to the standard chemical measurements. Coupled with watershed land use, nutrient data lent evidence for possible causes of nonpoint source pollution. For example, while percent forest in the watershed might be an indicator of stream condition, the correlation of DIN with percent RLU pointed to an anthropogenic source of pollution affecting the streams. Knowing the percentages of agriculture and of infrastructure in addition to RLU signified possible sources of particular nutrients in the streams.

Sites with more than $8 \%$ IS or $24 \%$ RLU showed lower habitat-assessment scores, increased sediment and nutrient load, and a shift in biotic taxa composition from sensitive to insensitive species. Results from our study of streams along a gradient of percent RLU were consistent with studies from other geographic regions and provide important data on the effects of increasing RLU on Rhode Island coastal streams.

Acknowledgements We are grateful to Walter Berry, Jim Latimer, and Tim Gleason for their support and helpful discussions during the preparation of this manuscript. We also thank Sandra Benyi, Rick McKinney, and Naomi Detenbeck for their thoughtful reviews. Our thanks also go to the residents of the neighborhoods where some of our sites were located. They were welcoming to us, interested in the condition of their streams, and helpful in providing local historical information. Although the research described in this article has been funded wholly by the U.S. Environmental Protection Agency, it has not been subjected to Agency-level review. Therefore, it does not necessarily reflect the views of the Agency. Mention of trade names or commercial products does not constitute endorsement or recommendation for use. Contribution Number NHEERLAED-06-068

\section{References}

Allan, J. D. (2004). Landscapes and riverscapes: The influence of land use on stream ecosystems. Annual Review of Ecology and Systematics, 35, 257-284.

American Society for Testing and Materials (2000a). Standard guide for selecting stream-net sampling devices for collecting benthic macroinvertebrates, D 4556-85 (Reapproved 1995). In Annual Book of ASTM Standards, Vol. 11.05 (pp. 78-86). Philadelphia, PA: American Society for Testing and Materials.

American Society for Testing and Materials (2000b). Standard practice for collecting benthic macroinvertebrates with
Surber and related type samplers, D 4557-85 (Reapproved 1995). In Annual Book of ASTM Standards, Vol. 11.05 (pp. 87-88). Philadelphia, PA: American Society for Testing and Materials.

Anderson, J. R., Hardy, E. E., Roach, J. T., \& Witmer, R. E. (1976). A land use and land cover classification system for use with remote sensor data. Geological Survey Professional Papers, Paper 964. Washington, D.C.: U.S. Dept. of Interior, U.S. Government Printing Office.

Arnold, C. L. Jr., \& Gibbons, C. J. (1996). Impervious surface coverage - the emergence of a key environmental indicator. Journal of the American Planning Association, 62, 243-258.

Barbour, M. T., Gerritsen, J., Snyder, B. D., \& Stribling, F. B. (1999). Rapid bioassessment protocols for use in streams and wadeable rivers: periphyton, benthic macroinvertebrates, and fish (2nd ed.) EPA 841-B-99-002. Washington, D.C.: Office of Water, U.S. Environmental Protection Agency.

Benke, A. C., Willke, G. E., Parrish, F. K., \& Stites, D. L. (1981). Effects of urbanization on stream ecosystems. ERC07-81. Atlanta, GA: Georgia Institute of Technology.

Campo, K. W., Flanagan, S. M., \& Robinson, K. W. (2003). Water quality of selected rivers in the New England coastal basins in Maine, Massachusetts, New Hampshire, and Rhode Island, 1998-2000. Water-Resources Investigations Report 03-4210. Reston, VA: U.S. Geological Survey

Carroll, G. D., \& Jackson, C. R. (2005). Discussion No. 02059D. Journal of the American Water Resources Association, 41, 219-220.

Chu, E. W., \& Karr, J. R. (2001). Environmental impact, concept and measurement of. In S. A. Levin (Ed.), Encyclopedia of biodiversity, Vol. 2 (pp. 557-577). Orlando, FL: Academic Press.

Coles, J. F., Cuffney, T. F., McMahon, G., \& Beaulieu, K. M. (2004). The effects of urbanization on the biological, physical, and chemical characteristics of coastal New England streams. Professional Paper 1695. Reston, VA: U.S. Geological Survey.

da Silva, S. N. (2003). A multiple scale approach to assessing the biological integrity of Rhode Island streams. Master's thesis, University of Rhode Island.

Deacon, J. R., Soule, S. A., \& Smith, T. E. (2005). Effects of urbanization on stream quality at selected sites in the Seacoast region in New Hampshire, 2001-03. Scientific Investigations Report 2005-5103. Reston, VA: U.S. Geological Survey

Diamond, D. H. (1997a). Determination of ammonia in brackish or seawater by flow injection analysis colorimetry. QuikChem Method 31-107-06-1-C for Lachat Instruments. Milwaukee, WI: Lachat Instruments.

Diamond, D. H. (1997b). Determination of nitrate in brackish or seawater by flow injection analysis. QuikChem Method 31-107-04-1-A for Lachat Instruments. Milwaukee, WI: Lachat Instruments.

Durborow, R. M., Crosby, D. M., \& Brunson, M. W. (1997). Nitrite in fish ponds, Publication No. 462. Stoneville, MS: Southern Regional Aquaculture Center.

Freeman, P. L., \& Schorr, M. S. (2004). Influence of watershed urbanization on fine sediment and macroinvertebrate 
assemblage characteristics in Tennessee Ridge and valley streams. Journal of Freshwater Ecology, 19, 353-362.

Gregory, S. V., Swanson, F. J., McKee, W. A., \& Cummins, K. W. (1991). An ecosystem perspective of riparian zone: Focus on links between land and water. BioScience, 41, $540-551$.

Hellawell, J. M. (1978). Macroinvertebrate methods. In Biological surveillance of rivers: A biological monitoring handbook (pp. 35-90). Dorchester: Dorset Press.

Hewlett, R. (2000). Implications of taxonomic resolution and sample habitat for stream classification at a broad geographic scale. Journal of the North American Benthological Society, 19, 352-361.

Hilsenhoff, W. L. (1987). An improved biotic index of organic stream pollution. Great Lakes Entomologist, 20, 31-40.

Huberty, A., \& Diamond, D. (1998). Determination of phosphorus by flow injection analysis colorimetry. QuikChem Method 31-115-01-3-A for Lachat Instruments. Milwaukee, WI: Lachat Instruments.

Hudak, P. F., \& Banks, K. E. (2006). Compositions of first flush and composite storm water runoff in small urban and rural watersheds, north-central Texas. Urban Water Journal, 3, 43-49.

Jones, R. C., \& Clark, C. C. (1987). Impact of watershed urbanization on stream insect communities. Water Resources Bulletin, 23, 1047-1055.

Karr, J. R. (1991). Biological integrity: A long-neglected aspect of water resource management. Ecological Applications, 1, 66-84.

Karr, J. R., \& Chu, E. W. (1999). Restoring life in running waters. Washington, D.C.: Island Press.

Karr, J. R., \& Schlosser, I. J. (1978). Water resources and the land-water interface. Science, 201, 229-234.

Kerans, B. L., \& Karr, J. R. (1992). Aquatic invertebrate assemblages: Spatial and temporal differences among sampling protocols. Journal of the North American Benthological Society, 11, 377-390.

Klemm, D. J., Blocksom, K. A., Thoeny, W. T., Fulk, F. A., Herlihy, A. T., Kaufmann, P. R., et al. (2002). Methods development and use of macroinvertebrates as indicators of ecological conditions for streams in the mid-Atlantic highlands region. Environmental Monitoring and Assessment, 78, 169-212.

Lussier, S. M., Enser, R. W., da Silva, S. N., \& Charpentier, M. (2006). Effects of habitat disturbance from residential development on breeding bird communities in riparian corridors. Journal of Environmental Management, 38, 504-521.

McBride, M., \& Booth, D. B. (2005). Urban impacts on physical stream condition: Effects of spatial scale, connectivity, and longitudinal trends. Journal of the American Water Resources Association, 41, 565-580.

Megan, M. H., Nash, M. S., Neale, A. C., \& Pitchford, A. M. (2006). Biological integrity in mid-Atlantic coastal plains headwater streams. Environmental Monitoring and Assessment, 124, 141-156. doi: 10.1007/s10661-006-9214-9.

Meyer, J. L., Paul, M. J., \& Taulbee, W. K. (2005). Stream ecosystem function in urbanizing landscapes. Journal of the North American Benthological Society, 24, 602-612.

Moore, A. A., \& Palmer, M. A. (2005). Invertebrate biodiversity in agricultural and urban headwater streams: Implica- tions for conservation and management. Ecological Applications, 15, 1169-1177.

Morley, S. A., \& Karr, J. R. (2002). Assessing and restoring the health of urban streams in the Puget Sound Basin. Conservation Biology, 16, 1498-1509.

Morrison, D. F. (2005). Multivariate statistical methods (4th ed). Belmont, CA.: Brooks/Cole Thomson Learning.

Naiman, R. J. (Ed) (1992). Watershed management: balancing sustainability and environmental change. New York: Springer-Verlag.

Omernik, J. M. (1987). Ecoregions of the conterminous United States. Map (scale 1:7,500,00). Annals of the Association of American Geographers, 77, 118-125.

Omernik, J. M., Abernathy, A. R., \& Male, L. M. (1981). Stream nutrient levels and proximity of agricultural and forest land to streams: Some relationships. Journal of Soil and Water Conservation, 36, 227-231.

Osborne, L. L., \& Wiley, M. J. (1988). Empirical relationships between land use/cover and stream water quality in an agricultural watershed. Journal of Environmental Management, 26, 9-27.

Parsons, M., \& Norris, R. H. (1996). The effect of habitat-specific sampling on biological assessment of water quality using a predictive model. Freshwater Biology, 36, 419-434.

Peterson, B. J., Wollheim, W. M., Mulholland, P. J., Webster, J. R., Meyer, J. L., Tank, J. L., et al. (2001). Control of nitrogen export from watersheds by headwater streams. Science, 292, 86-90.

Plafkin, J. L., Barbour, M. T., Porter, K. D., Gross, S. K., \& Hughes, R. M. (1989). Rapid bioassessment protocols for use in streams and rivers: Benthic macroinvertebrates and fish. Washington, D.C.: U.S. Environmental Protection Agency. EPA/444/4-89-001.

Potter, K. M., Cubbage, F. W., \& Schaberg, R. H. (2005). Multiple-scale landscape predictors of benthic macroinvertebrate community structure in North Carolina. Landscape and Urban Planning, 71, 77-90.

Pratt, J. M., Coler, R. A., \& Godfrey, P. J. (1981). Ecological effects of urban storm-water runoff on benthic macroinvertebrates inhabiting the Green River, Massachusetts. Hydrobiologia, 83, 29-42.

Resh, V. H. (1979). Sampling variability and life history features: Basic considerations in the design of aquatic insect studies. Journal of the Fisheries Research Board of Canada, 36, 290-311.

Resh, V. H., \& McElravy, E. P. (1993). Contemporary quantitative approaches to biomonitoring using benthic macroinvertebrates. In D. M. Rosenberg \& V. H. Resh (Eds.), Freshwater biomonitoring and benthic macroinvertebrates (pp. 159194). New York: Chapman and Hall.

Resh, V. H., Norris, R. H., \& Barbour, M. T. (1995). Design and implementation of rapid assessment approaches for water resource monitoring using benthic macroinvertebrates. Australian Journal of Ecology, 20, 108-121.

Rhode Island Department of Environmental Management (RIDEM) (2002). State of Rhode Island 2002 section 305(b) state of the state's waters report. Providence, RI: Office of Water Resources.

RIGIS (Rhode Island Geographic Information System) (1986). RI division of planning, Dept. of administration, statewide planning program, 1 Capitol Hill, Providence, 
RI. Retrieved from http://www.planning.state.ri.us/gis/ gishome.htm

Rosenfeld, J. S., \& Hudson, J. J. (1997). Primary production, bacterial production, and invertebrate biomass in pools and riffles in southern Ontario streams. Archiv für Hydrobiologei, 139, 301-316.

Roth, N. E., Allan, J. D., \& Erickson, D. O. (1996). Landscape influences on stream biotic integrity assessed at multiple spatial scales. Landscape Ecology, 11, 141-156.

Roy, A. H., Faust, C. L., Freeman, M. C., \& Meyer, J. L. (2005). Reach-scale effects of riparian forest cover on urban stream ecosystems. Canadian Journal of Fisheries and Aquatic Sciences, 62, 2312-2321.

Roy, A. H., Rosemond, A. D., Leigh, D. S., Paul, M. J., \& Wallace, J. B. (2003). Habitat-specific responses of stream insects to land cover disturbance: Biological consequences and monitoring implications. Journal of the North American Benthological Society, 22, 292-307.

Schroeder, S. (1997). Determination of nitrite in brackish or seawater by flow injection analysis. QuikChem Method 31-107-05-1-A for Lachat Instruments. Milwaukee, WI: Lachat Instruments.

Snyder, C. D., Young, J. A., Villella, R., \& Lemarié, D. P. (2003). Influences of upland and riparian land use patterns on stream biotic integrity. Landscape Ecology, 18, 647-664.

Steedman, R. J. (1988). Modification and assessment of an index of biotic integrity to quantify stream quality in southern Ontario, Canada. Canadian Journal of Fisheries and Aquatic Sciences, 45, 492-501.

Sweeney, B. W. (1992). Streamside forest and the physical, chemical, and trophic characteristics of Piedmont streams in eastern North America. Water Science and Technology, 26, 2653-2673.
Urban, M. C., Skelly, D. K., Burchsted, D., Price, W., \& Sowry, S. (2006). Stream communities across a rural-urban landscape gradient. Diversity and Distributios, 12, 337350 .

Vitousek, P. M., Aber, J. D., Howarth, R. W., Likens, G. E., Matson, P. A., Schindler, D. W., et al. (1997). Human alteration of the global nitrogen cycle: Sources and consequences. Ecological Applications, 7, 737-750.

Walsh, C. J., Roy, A. H., Feminella, J. W., Cottingham, P. D., Groffman, P. M., \& Morgan II, R. P. (2005). The urban stream syndrome: Current knowledge and the search for a cure. Journal of the North American Benthological Society, 24, 706-723.

Wang, L., \& Kanehl, P. (2003). Influences of watershed urbanization and instream habitat on macroinvertebrates in cold water systems. Journal of the American Water Resources Association, 39, 1181-1196.

Wang, L., Lyons, J., Kanehl, P., \& Gatti, R. (1997). Influences of watershed land use on habitat quality and biotic integrity in Wisconsin streams. Fisheries, 22, 6-12.

Wetzel, R. G. (1975). The nitrogen cycle. In Limnology (pp. 186-214). Philadelphia, PA: W.B. Saunders Co.

Wheeler, A. P., Angermeier, P. L., \& Rosenberger, A. E. (2005). Impacts of new highways and subsequent landscape urbanization on stream habitat and biota. Reviews in Fisheries Science, 13, 141-164.

Wigand, C., Comeleo, R., McKinney, R., Thursby, G., Chintala, M., \& Charpentier, M. (2001). Outline of a new approach to evaluate ecological integrity of salt marshes. Human and Ecological Risk Assessment, 7, 1541-1554.

Zar, J. H. (1999). Biostatistical analysis. Upper Saddle River, NJ: Prentice-Hall. 